\title{
Relinquo ad ipsa tabula de argento... La orfebrería en los testamentos catalanes de los siglos XI-XIII
}

\author{
Joan DURAN-PORTA \\ Universitat Autònoma de Barcelona \\ Joan.Duran@uab.cat
}

\section{RESUMEN}

La abundante documentación conservada de época plenomedieval permite aproximarse con notable rigor a la orfebrería románica catalana, pese a tratarse de una producción prácticamente desaparecida del todo. El presente artículo analiza específicamente los legados testamentarios en orfebrería o para la producción de orfebrería, con el objetivo de dilucidar los diversos usos sociales o simbólicos de las piezas, y su importancia económica fundamental en las transmisiones patrimoniales entre las élites laicas y el estamento eclesiástico de la sociedad entre los siglos XI y XIII.

Palabras clave: Orfebrería, Románico, Fuentes documentales, Testamentos, Frontal de altar.

\section{Relinquo ad ipsa tabula de argento... Silverwork in Catalan Wills of the $11^{\text {th }}-13^{\text {th }}$ Centuries}

\begin{abstract}
Although very little Catalan metalwork from Romanesque Middle Ages remain, its importance as an artistic production and its social relevance are firmly revealed by documentary sources. This paper is specifically focused on wills from the 11th to the 13th Centuries. It analyse both legacies in metalwork and testamentary bequests for the creation of sumptuary objects, with the aim of elucidating the social and financial uses of these objects, and their role in the patrimonial transfers between secular elites and the ecclesiastical establishment of the medieval society.
\end{abstract}

Key words: Metalwork, Romanesque, Documentary sources, Testaments, Altar Frontals.

* El estudio que aquí se presenta se inscribe en el Proyecto de Investigación Magistri Cataloniae. Artistas, patronos y público. Cataluña y el Mediterráneo (siglos XI-XV), dirigido por Manuel Castiñeiras (MICINN HAR2011-23015). 
La trascendencia social de las artes orfebres resulta ciertamente significativa en el pleno Medievo, desde luego superior a la de otras técnicas artísticas, debido al valor crematístico y también simbólico de los materiales utilizados en ellas. Los objetos creados con metales preciosos y otros ricos componentes son motivo permanente de fascinación general, asumen a menudo connotaciones morales o alegóricas asociadas con la devoción y el culto e, incluso, pueden ser capaces de despertar el aprecio puramente estético de sus contempladores. Son además argumentos de vital importancia para el desarrollo normativizado de los intercambios patrimoniales entre la Iglesia y las élites laicas de la sociedad feudal, pues proporcionan a las instituciones eclesiásticas una decisiva capacidad de tesaurización y un fondo de recursos financieros fundamental para sus incesantes actividades económicas.

El estudio del comportamiento social de la orfebrería debe realizarse sobre una base documental que permita trascender el análisis estrictamente "artístico" de las piezas conservadas, para detallar su contexto cultural y mercantil. Para el caso de la orfebrería catalana de época románica, este tipo de aproximación contextual es prácticamente la única posible, ya que el número de obras de producción local de cierta categoría que ha llegado hasta nosotros es francamente muy escaso. Sí abundan los modestos utensilios litúrgicos procedentes de iglesias o capillas rurales, cuya rutinaria producción ha merecido muy poca atención por parte de la bibliografía, comprensiblemente ${ }^{1}$.

Lo poco conservado contrasta, sin embargo, con la considerable cantidad de informaciones sobre piezas orfebres contenidas en la prolífica documentación que de los siglos medievales se conserva en los archivos catalanes. Toda esa información apenas ha sido utilizada por la historia del arte, tal vez porque proporciona muy pocas noticias (casi ninguna) que refieran a objetos conservados. Cierto es que los historiadores pioneros del arte medieval catalán recogieron algunos datos sobre las obras documentadas más relevantes, en particular sobre los frontales de altar que existían en las grandes catedrales y templos monásticos del s. XI, pero los resultados de estos seminales estudios tienden a centrarse solo en una revisión formal de las obras desaparecidas, o bien se dedican a trazar un panorama de base tipológica sobre los objetos mencionados en las fuentes, especialmente los de índole litúrgica ${ }^{2}$. Ambas aproximaciones son, por supuesto, interesantísimas, pero suelen descuidar el análisis de los contextos funcionales o sociofuncionales en los que se mueven los objetos suntuarios.

1 Entre lo conservado de cierto valor destaca, por ejemplo, un pequeño incensario esmaltado de mediados del s. XII (en el MNAC), un par de cruces de plata quizás de finales del s. XIII, y las cubiertas igualmente tardías del Missal de Sant Ruf en la catedral de Tortosa. Dichas piezas se comentan, junto con otras menores, en los (escasos) estudios panorámicos sobre la orfebrería catalana publicados en las últimas décadas: J. BARRACHINA, "Romànic. Arts sumptuàries", Art Català. Estat de la qüestió, Ve congrés del CEHA, Barcelona, 1984, pp. 149-167; N. DE DALMASES, Argenters i joiers de Catalunya, Barcelona, 1985, pp. 8-16; y E. CARBONELL et al., "Les arts de l'objecte", Catalunya Romànica, vol. XXVII, Barcelona, 1998, pp. 140-143. Sobre las piezas conservadas del Rosellón hay un artículo reciente, de notable interés: G. DALMAU, "Orfèvrerie nord-catalane des Xe-XIIIe siècles, un essai de corpus", Les Cahiers de Saint-Michel de Cuxa, XLI (2010), pp. 113-120.

2 En particular: J. GUDIOL I CUNILL, Nocions d'arqueologia sagrada catalana, Vic, 1902, caps. 31-35 (ed. revisada 1931-1933); y F. DURAN CAÑAMERAS, La orfebrería catalana, Barcelona, 1915. 
El objetivo de este breve artículo es, precisamente, profundizar en dichos contextos, y reconocer la orfebrería catalana del románico no desde su presencia física sino desde su comportamiento documental. Aunque las menciones a objetos de arte suntuario aparecen en documentos de tipologías bastante diversas (inventarios, dotaciones, compra-ventas), he reducido aquí el alcance del análisis a la categoría diplomática de los testamentos, quizás la que permite conocer mejor el comportamiento del hombre medieval (y de la mujer) para con este tipo de objetos de lujo. La presencia de la orfebrería en los legados testamentarios es abundantísima, y casi siempre relevante. Suele tener un papel destacado junto con los elementos de vestuario y el ajuar doméstico, siempre complementando los legados principales que son, invariablemente, los relacionados con las tierras.

La encuesta realizada sobre las fuentes se ha centrado en las colecciones catalanas publicadas, que son un impresionante y utilísimo corpus de información para el investigador. Ha reportado un número aproximado de 150 testamentos en los que se mencionan piezas de orfebrería, indistintamente textos redactados a petición del testador o publicaciones sacramentales de sus últimas voluntades, juradas por sus albaceas. En dichos testamentos aparecen objetos tanto de función religiosa como, bastante más habitualmente, de uso profano, en ambos casos de tipologías harto diversas y con un indiscutible predominio de la plata como material de producción, pues aunque el oro es el metal más valioso y apreciado en todos los siglos medievales, su coste y la dificultad de su acceso reducen muy considerablemente su presencia ${ }^{3}$.

Los objetos religiosos son fundamentalmente parte del instrumental litúrgico de las iglesias. Aunque hay algunas excepciones, en general no suelen aparecer como propiedad de los testadores y objeto de transmisión patrimonial, sino que funcionan como "receptores", es decir: son objetos para la fabricación o para la reforma de los cuales se proporcionan legados. En general, los objetos más destacados por número de apariciones son los cálices eucarísticos, luego las cruces y en menor medida los incensarios, cuya importancia y calidad (las más veces son mencionados de plata) resultan en cierto modo sorprendentes ${ }^{4}$. Otras piezas mencionadas son los candelabros, las lámparas (de aceite), las pequeñas ampollas o botellines (ampullae) para contener el crisma u otros óleos bendecidos, los vasos para el lavatorio (urceolum o urceos), y lo que parecen ser pequeñas lipsanotecas (capsae) para la custodia de reliquias.

Como digo, los objetos profanos son especialmente abundantes en los testamentos, y forman además el grueso de legados directos entre testadores y herederos. Cabe distinguir tres categorías fundamentales de ellos: las piezas de la vajilla, las joyas y los elementos metálicos del armamento y los arneses de las monturas.

\footnotetext{
3 Además de la plata y el oro, en los documentos se mencionan de forma puntual otros metales igualmente preciosos, como el bronce y el cobre (que parecen confundirse), o menos nobles como el estaño y el latón. Solo en alguna ocasión está documentado el marfil, mientras que son relativamente habituales las piedras preciosas (gemis, petras, lapides), que se utilizan sobre todo para la decoración de anillos o cruces. Solo a partir del s. XIII se mencionan objetos esmaltados en opus lemovicensis, aunque luego está claro que su importación es muy abundante.

4 La importancia documental de los incensarios (turibula, incensaria) contrasta con cierto desinterés historiográfico hacia este tipo de piezas, aunque recientemente subsanado con el monumental catálogo de $\mathrm{H}$. WESTERMANN-ANGERHAUSEN, Mittelalterliche Weihrauchfässer von 800 bis 1500, Petersberg, 2014.
} 
Los objetos pertenecientes a la vajilla de lujo ${ }^{5}$ son indudablemente los más abundantes. Aparecen en un porcentaje alto de los testamentos conservados, y con un catálogo de tipologías muy variado, en el que predominan los recipientes para la bebida y el almacenaje de líquidos, que reciben distintos nombres en atención a sus características específicas: cifos, anaps, copas, vasa... También se mencionan útiles para la comida (gradals, escudellas, cucharas) y para el lavado de las manos (aquamanile). Cuando las piezas son muy abundantes se mencionan todas genéricamente como vascula argentea o vascula aurea et argentea, pero normalmente se pone bastante cuidado en detallar las piezas una por una.

Entre las joyas mencionadas destacan sobremanera los anillos, que son parte del adorno tanto femenino como masculino, y una posesión típica y consubstancial de obispos y altas jerarquías eclesiásticas. Además de su valor estético, está claro que en épocas tempranas algunos de estos anillos debían tener función sigilar, es decir funcionaban como sellos de estampación para la garantía de cierres y acaso también para la validación de documentos ${ }^{6}$. La circulación de anillos, no solo entre eclesiásticos sino también entre laicos (y entre unos y otros), está perfectamente documentada: en el testamento del año 1040 del obispo Eriball de Urgell, por ejemplo, se mencionan hasta cinco anillos distintos que son legados respectivamente a los titulares de otras cinco diócesis catalanas; dos de dichos anillos, afirma el texto, habían pertenecido antes al conde Ermengol I, fallecido 30 años atrás, y otro sido propiedad de Arnau Mir de Tost, el célebre magnate de la frontera urgelitana ${ }^{7}$.

Al margen de los anillos, el ornato femenino podía ser notablemente rico. Incluía principalmente broches o cierres de vestido, que aparecen en casi todos los testamentos de féminas conservados y a los que se alude generalmente con el término de nuscas o noschas. También pueden recibir otros nombres, quizás según el modelo de broche al que se pretende aludir, como fíbulas, nodellos o-en romance-crozadors y encrodadors. Incluyo en esta categoría de joyas los objetos de tocador, tales como espejos, peines o perfumadores, cuya propiedad parece reservada desde luego (cuando son manufacturas preciosas) a las mujeres de más alto linaje ${ }^{8}$. Incluso en cierto modo también los juegos de ajedrez pueden ser considerados como joyas, por lo menos los labrados en materiales preciosos como el marfil o el cristal de roca ${ }^{9}$; su presencia es

5 Cabe pensar que este tipo de vajilla, preferentemente de plata, no debía utilizarse diariamente. En cualquier caso, siempre se distingue de la vajilla cotidiana y de los utensilios de almacenaje domésticos, que se mencionan siempre de forma genérica como vascula minora et maiora.

6 Sobre los anillos sigilares conocidos en Cataluña: R. GRAELLS, 'Dactylothecae cataloniae'. El col-leccionisme de glíptica a Catalunya abans de 1900, Barcelona, 2011, pp. 115-119.

7 El testamento de Eriball se ha publicado en múltiples ocasiones. Utilizo aquí una de las recientes: I. LLOP, Col-lecció diplomàtica de Sant Pere de Casserres, Barcelona, 2009, I, doc. 160, pp. 181-185.

8 El testamento de Arsenda de Tost, esposa de Arnau Mir, es especialmente rico en este tipo de enseres, incluyendo varios perfumadores (pumbos), un espejo de plata (speculum indium), varios broches (assfilbulis), así como anillos de oro con piedras (anulos de auro cum iemas et gegonciis) y botones también dorados (mudellis de auro). Editado en: R. CHESÉ, Col-lecció diplomàtica de Sant Pere d'Àger fins 1198, Barcelona, 2011, I, doc. 87 , p. 326-331.

9 Los juegos en cristal de roca se suponen de origen islámico (fatimí). Sobre la importación de este tipo de piezas y otros objetos elaborados en cristal de roca: M. CASAMAR y F. VALDÉS, "Arrotomas Irakes", Homenatge a mossèn Jesús Tarragona, Lleida, 1996, pp. 67-88. 
inusitadamente habitual en la documentación catalana del pleno Medievo, sobre todo en el entorno del condado de Urgell, quizás por la proximidad de las tierras musul$\operatorname{manas}^{10}$.

La tercera categoría de objetos laicos la forman las piezas suntuarias del armamento y los arneses de las caballerías, que son un legado característico, por supuesto, de la nobleza feudal. Entre las armas destacan los pomos de espada y las vainas, y entre los arneses, básicamente los frenos (frenum), es decir los elementos metálicos de la brida que el animal lleva en la boca, y también las sillas de montar (sellas), que parece que podían llegar a ser bastante exuberantes. Ambas piezas eran muy relevantes desde el punto de vista económico y sin duda se regalaban como presente diplomático, además de funcionar habitualmente como legado testamentario. En este sentido, en el testamento del obispo Sal·la de Urgell (1003) se menciona un freno con ornamentación ("frenum paratum") que el difunto obispo tenía como obsequio del conde Sunifredo II, y además una sella que le había regalado nada más y nada menos que el califa de Córdoba ("ipsa sella quod dedit mihi Algalipha")"

Además de evocar el amplio repertorio de piezas suntuarias producidas y transmitidas, las disposiciones testamentarias permiten indirectamente conocer otro tipo de datos que subyacen bajo las intenciones implícitas o explícitas de los testadores, datos significativos sobre los modelos de producción de las artes suntuarias en el contexto del románico catalán, y sobre los sistemas y procesos de utilización socioeconómica en los que participan los mismos.

Aunque las piezas orfebres nunca representan el principal activo en los testamentos plenomedievales (lo son los bienes territoriales y las rentas obtenidas de ellos), sí aparecen de forma habitual en las últimas disposiciones de las gentes acaudaladas, incluso en mayor cantidad que los legados monetarios. Está claro, además, que estaba muy generalizada la posesión, por lo menos, de algún tipo de vajilla de plata, y que su transmisión patrimonial se fundaba sobre costumbres muy arraigadas. Evidentemente, las élites más ricas y poderosas disponían de conjuntos especialmente amplios de bienes orfebres, pero es interesante constatar que, luego, los modelos de actuación legataria no eran significativamente distintos.

Incluso hay pocas diferencias entre las actuaciones testamentarias de clérigos y de laicos, en las que predominan siempre los objetos de uso profano y las donaciones a particulares próximos o bien a instituciones eclesiásticas estrechamente relacionadas con los difuntos. Sí parecen ser, los eclesiásticos, lógicamente más proclives a la posesión y transmisión de objetos suntuarios, lo que quizás debe explicarse por el avance del reformismo gregoriano y la progresiva limitación a los clérigos de la posesión

10 De hecho, la referencia más antigua al ajedrez en la Europa cristiana está en el testamento del conde Ermengol I del año 1007: C. BARAUT, "Els documents, dels anys 981-1010, de 1'Arxiu Capitular de la Seu d'Urgell", Urgellia, III (1980), doc. 300, pp. 131-132. Se conservan las conocidas piezas de cristal de roca que pertenecieron a Arnau Mir de Tost: F. FITÉ, "El lot de peces d'escacs de cristall de roca del Museu Diocesà de Lleida, procedents del Tresor de la col·legiata d'Àger", Acta historica et archaeologica Mediaevalia, 5-6 (1984-1985), pp. 281-312. Había también juegos elaborados en materiales más humildes, como los de hueso ("ipsos escachs et tabulas de osso") que legaba el levita Ramon a su hermano en 1045: J. BAUCELLS et al., Diplomatari de l'Arxiu Capitular de la catedral de Barcelona, Barcelona, 2006, III, doc. 687, pp. 1166-1171.

11 C. BARAUT, op. cit., 1980, doc. 288, pp. 120-1210. 
privada de haciendas y honores territoriales. Tampoco hay excesivas diferencias entre los legados masculinos y los femeninos (aunque estos son numéricamente bastante escasos), lo que no resulta sorprendente a tenor de la notable capacidad jurídica de la mujer en la época con que tratamos, por lo menos en el contexto de la Europa meridional (y siempre en relación a los estratos más elevados de la sociedad de la época).

Las piezas de orfebrería pueden ser concedidas por una parte a personas físicas, que son casi siempre familiares o figuras próximas a los testadores, y por otra parte a instituciones eclesiásticas, también generalmente cercanas al difunto ${ }^{12}$. Desde luego, la trascendencia de las donaciones del segundo tipo es enorme, tiene sobradas justificaciones teológicas y morales y proporciona, además, ganancias espirituales directas y tangibles para los testadores y sus familiares, cuya remisión de pecados y eterna salvación era convenientemente satisfecha gracias a ellas. En la mayoría de textos está clara la voluntad de equiparar el bienestar de los descendientes con el cuidado del alma del difunto por parte de los oratore terrenales, lo que por supuesto ocupa no solo a los legados en orfebrería sino a todo tipo de herencias.

Las donaciones a catedrales, canónicas, parroquias o monasterios permitían ciertamente a los hombres mantener la esperanza en la salvación, y en contrapartida proporcionaban a los templos una fuente de riqueza de primer orden. Aunque los textos nunca son explícitos en este sentido, parece sensato asumir que este sistema de contraprestaciones era bien comprendido por todo el mundo y que, al margen de las ganancias morales, los testadores asumían que este modo de proteger y agrandar los beneficios eclesiásticos compensaba los posibles agravios y conflictos que hubiera entre la correosa nobleza feudal y la no menos aguerrida casta de eclesiásticos afines al reformismo. En cualquier caso, los legados proporcionaban a los templos una riqueza material que podía ser directamente tesaurizada o fácilmente reconvertible en objetos tesaurizables, y que posteriormente podía ser utilizada como fondo financiero para las actividades económicas de las instituciones religiosas, que eran muy abundantes. Es significativo que pese a las prohibiciones y discursos contra la venta o empeño de estos bienes por parte de las iglesias, estos se producían de forma generalizada y sin demasiada controversia, de modo que los tesoros eclesiásticos medievales servían sobre todo a fines económicos, y solo de forma secundaria a otros menesteres más afines a la espiritualidad ${ }^{13}$.

12 En efecto, los legados se ofrecen básicamente a templos del área geográfica del testador, y solo ocasionalmente a iglesias extranjeras, que suelen ser centros internacionales de peregrinación (San Pedro de Roma, el Santo Sepulcro) o bien templos singularmente próximos al contexto cultural catalán, caso de las abadías occitanas de Santa Fe de Conques o de San Gil de Nimes. Un caso aparte es el testamento del rey Alfonso el Casto, ya de 1194, cuya magnanimidad metalística (en forma de cálices e incensarios) se dirige a una extensa nómina de iglesias internacionales: J. ALTURO, L'Arxiu antic de Santa Anna de Barcelona del 942 al 1200: aproximació històrico-lingüística, Barcelona-Vic, 1985, III, doc. 598, pp. 149-159.

13 La bibliografía sobre los tesoros medievales se ha ampliado bastante en los últimos años. Véase, entre muchos otros ejemplos: J.-P. CAILLET, "Les trésors ecclésiastiques, de l'Antiquité tardive à l'époque romane: permanences de l'esprit des origines", Trésors et routes de pèlerinages dans l'Europe médiévale, Études publiées a l'occasion des journées d'inauguration du Centre Européen d'Art et de Civilisation Médiévale, Conques, 1994, pp. 33-46; P. GEORGE, "Définition et fonction d'un trésor d'église", Bulletin du centre d'études médiévales d'Auxerre, 9 (2005), http://cem.revues.org/719. 
Aunque existen ocasionalmente los legados incondicionados, en realidad las donaciones testamentarias de objetos suntuarios a instituciones eclesiásticas se realizan en base a tres distintas condiciones u objetivos principales. En primer lugar, es frecuente que dichos legados no se vinculen más que a las habituales actividades oratorias de las comunidades religiosas para con el futuro de las almas difuntas. Este tipo de legados, pro anima o per missas, son relativamente abundantes. En ocasiones estos legados se vinculan de forma sutil a la financiación de la sepultura del testador en la iglesia beneficiaria, aunque desde luego nunca aparecen explícitamente como pago directo para el sufragio de la tumba; sin embargo a menudo es fácilmente perceptible que se trata de una contraprestación, como ocurre por ejemplo en el testamento sacramental de la hija del conde barcelonés Borrell II, Ermengarda, donde se indica la donación ad sepeliendum de su cuerpo al Monasterio de Sant Cugat del Vallès, junto con una portentosa cantidad de metal en objetos de lujosa vajilla ${ }^{14}$.

En segundo lugar, son también habituales las donaciones ad opera, es decir destinadas a la financiación de algún tipo de actividad constructora, restauradora o decorativa en la iglesia que los recibe. Los objetos legados con este fin no suelen ser significativos en sí mismos, pues lo que se toma en cuenta es el valor económico de sus materiales, gracias a los cuales conseguir los fondos necesarios para llevar a cabo las empresas que se plantean. Dichas empresas son bastante específicas, y aunque suelen ser de carácter constructivo, quizás resultan más interesantes cuando se dedican a la decoración interior. En 1076, por ejemplo, el magnate vallesano Ermengol Samarell legaba un cifo de plata para la decoración mural ("ad picturam") de la iglesia de Sant Pere de Vilamajor, lo que nos permite valorar en cierto modo los costes (bastante moderados) de una decoración de este tipo, en un templo ciertamente menor ${ }^{15}$.

Finalmente, el tercer gran objetivo de los legados en orfebrería es la creación de nuevos utensilios litúrgicos para las iglesias, o bien el embellecimiento de piezas preexistentes. La cantidad de testamentos que incluyen cláusulas de este tipo es extraordinariamente elevada, lo que responde sin duda a la necesidad de los templos de disponer de este tipo de productos, no necesariamente dedicados al culto, como decía, sino concienzudamente tesaurizados. La fabricación de objetos litúrgicos podía ser financiada con legados en moneda o en bienes de cualquier otra índole, pero es bien significativo que lo más habitual en estos casos sean las donaciones de otros objetos suntuarios. Es decir: se producen objetos litúrgicos preciosos a partir de los materiales de otros objetos preciosos, generalmente de uso profano. Se trata de un mecanismo inteligente y perfectamente articulado para el reaprovechamiento de materiales de lujo, siempre difíciles de conseguir, aunque tampoco debe descartarse la reutilización completa de objetos (incluso pasando de función profana a religiosa), que en todo caso no está suficientemente documentada en esta época, y que debió ser bastante más rara ${ }^{16}$. Está claro que algunos materiales se reaprovechaban directa-

14 Exactamente "parilios II de anaps argenteis, et gradal I obtimo, et cuzlars X.m ex argento": J. RIUS SERRA, Cartulario del monasterio de Sant Cugat del Vallès, Barcelona, 1945-1981, II, doc. 531, pp. $190-191$.

15 J. BAUCELLS et al., op. cit, 2006, IV, doc. 1305, pp. 2026-2031.

16 Son pocos los ejemplos conocidos en Cataluña, y siempre de época tardomedieval. Está el caso singular del relicario de coral parece que vinculado a la reina Isabel de Portugal, hija de Pedro el Ceremonioso, que 
mente, como las piedras preciosas, pero en general los metales (la plata y el oro sobre todo) se fundían antes de formar con ellos nuevas piezas. Cierto es que este proceso de reciclaje material no resulta casi nunca fácil de detectar en las fuentes escritas de la época, pero hay ejemplos que sí permiten intuirlo de forma suficientemente clara.

Los legados testamentarios para la fabricación de piezas suelen llevar la cláusula ad faciendam, y en general se destinan a la creación de cruces de altar o cruces procesionales, de cálices y patenas, y en menor medida de incensarios y otro tipo de útiles menores; un caso aparte es el de los frontales o tablas de altar, que ocupan un lugar muy destacado entre este tipo de donaciones, como veremos enseguida. Como decía, el proceso de reutilización de los metales parece bastante evidente en algunos casos concretos. Por ejemplo, en el legado de once cucharas de plata "ad ornandam crucem" que realiza en 1049 el archidiácono Sunyer de Vic para la iglesia de Santa Maria de Navàs, en el que se supone habría de utilizarse la plata para el laminado argénteo de la mencionada cruz, cuya alma de madera pudiera quizás existir con anterioridad, o no ${ }^{17}$. O en el legado, más tardío, de un cifo de plata, explícitamente donado por el obispo de Tortosa Ponç de Monells en 1193 para la fabricación de una lámpara de aceite ("ad faciendam lampadam") destinada al altar de San Juan de su catedral ${ }^{18}$.

Además de fundir metales para emplearlos en creaciones nuevas, los testamentos revelan que muchas piezas ya existentes eran objeto de mejoras o reformas. A menudo la intención de enriquecer las piezas es perfectamente explícita, como en el testamento del sacristán de la catedral de Urgell, Guillem, quien otorga en 1065 todo su oro y su plata a la cruz del altar de Santa María, para completarla ("ad perfeccionem iam dicta crux" ${ }^{19}$. O como en el testamento del año 1137 del archidiácono Bernat de Vic, quien lega un cifo de plata para que se fabriquen dos cálices en la catedral, uno para el altar mayor y otro para el altar de la cripta, y concede además varios anillos de oro expresamente para dorar ("ad deaurandum") dichos cálices. Un último ejemplo significativo: en 1148, otro canónico del capítulo de Vic, llamado Pere, lega 22 monedas de oro y seis anillos con piedras para restaurar y literalmente agrandar ("restaurandam et augendam") la cruz de oro del altar mayor de la catedral ausetana ${ }^{20}$.

En todo este tipo de procesos legatarios cabe destacar la importancia asumida por los frontales de altar como obras receptoras, es decir como piezas cuya fabricación y embellecimiento despiertan el interés de los testadores. Las donaciones ad tabula son efectivamente numerosas, y la envergadura de dichos frontales como piezas de

fue posiblemente en origen una pieza de vaiselle d'apparat para la lujosa mesa de la reina: J. DOMENGE y A. MOLINA, "Les 'nobles i riques ofrenes' d'Isabel de Portugal. Orfebreries de la reina santa", Princeses de terres llunyanes. Catalunya i Hongria a l'edat mitjana, Barcelona, 2009, pp. 316-319. Otro ejemplo conocido es el de una arqueta de marfil originaria del taller de los Embriachi florentinos, creada como depósito de un ajuar matrimonial pero conservada en la catedral de Barcelona en función de relicario para los restos de San Severo: F. FITÉ, “Arqueta de sant Sever”, Catalunya Medieval, Barcelona, 1992, pp. 254-255.

17 I. LLOP, op. cit., 2009, I, doc. 181, pp. 200-204.

18 A. VIRGILI, Diplomatari de la catedral de Tortosa (1062-1193), Barcelona, 1997, doc. 293, pp. 609611

19 J.M. MASNOU I PRATDESABA, Diplomatari de Ramon Gaufred, bisbe d'Osona: 1110-1145, Barcelona, 1991, II, doc. 87, pp. 211-216.

20 I. LLOP, op. cit., 2006, I, doc. 449, pp. 437-439. 
orfebrería de gran tamaño y valor material, así como su acusada dimensión artística, reclama que se les otorgue una atención particular.

Los frontales de orfebrería se mencionan siempre en la documentación testamentaria como tabulae, es decir como tablas de altar. La cuestión terminológica no es intrascendente, pues que yo conozca no se denominan nunca, al menos en Cataluña, ni antipendia ni tampoco pallia, vocablos que sin embargo ha utilizado muy frecuentemente la historiografía dedicada a su estudio. En realidad, estos dos términos refieren únicamente a cobertores textiles del altar, que acaso se sobreponían a dichas tablas; pero nunca identifican frontales sólidos ${ }^{21}$. Por otra parte, el concepto de tabula es notablemente polisémico y, además de designar a los frontales (o laterales) de altar, se utiliza para designar otro tipo de objetos, como las mesas del mobiliario doméstico o las piezas del juego "de tablas". En general es fácil distinguir estas acepciones en los textos, aunque a veces aparece algún caso conflictivo. Por ejemplo las tabulae auree que se mencionan en el testamento del rey Alfonso el Casto de 1194, que probablemente deban identificarse con las placas de un pequeño oratorio particular en forma de díptico ${ }^{22}$.

Cuando los textos refieren claramente al ornato del altar, surge una cuestión particularmente espinosa: ¿los legados ad tabula son específicamente destinados a los frontales, o en realidad se dirigen de forma genérica al conjunto del altar, que asume carácter jurídico como receptor de donaciones? El asunto no ofrece una lectura sencilla. Por una parte, es cierto que en numerosas ocasiones los testadores pretenden fabricar o renovar específicamente el mueble, y entonces los legados se dirigen inconfundiblemente a la tabla, al frontal. Sin embargo, cuando los textos no son concluyentes, a veces parece que con el legado ad tabula se dirijan simplemente las donaciones al altar correspondiente, que en realidad también puede ser considerado una tabula en su estructura formal, una mesa para el sacrificio. Hay ciertos casos en que esta segunda lectura parece pertinente, como en un testamento redactado por un tal Pere Sanç hacia 1174, en el que se dejan unos viñedos a la iglesia de Sant Pere de Llobera "et ad tabula Sancti Petri, ad ille qui servient cotidie, die et nocte"23. En ejemplos de este tipo las dudas predominan sobre las certezas: ¿el término tabla identifica directamente el altar? ¿Cabe suponer que cuando se cita un altar como tabula, puede existir también un frontal?

En fin, planteadas estas incertidumbres, también hay que decir que abundan los legados testamentarios clara e indiscutiblemente vinculados a la creación o reforma

21 De hecho, el término antipendium ni siquiera parece que se pueda localizar en ningún caso en la documentación catalana. Con el vocablo pallia, que sí es habitual en las fuentes, se denominan genéricamente tipos bastante variados de telas litúrgicas (algunos vinculados efectivamente al revestimiento del altar), además de varias prendas de vestir. Hay una tesis doctoral reciente sobre el vocabulario textil en la documentación catalana antigua: L. TRIAS FERRI, La terminologia tèxtil a la documentació llatina de la Catalunya altomedieval, Universitat de Barcelona, 2012 (véase, en particular, pp. 96-100 y 260-264).

22 Para el testamento del monarca, véase nota 12. En época algo posterior se denominan igualmente tabule (o en romance: taules) las cubiertas de evangeliarios desvinculadas del códice y reutilizadas como imágenes de altar. Hay varios ejemplos hispanos en relación con piezas esmaltadas de obra de Limoges: F. ESPAÑOL, "Los esmaltes de Limoges en España”, De Limoges a Silos, Madrid, 2001, p. 91.

23 A. BACH I RIU, Diplomatari de l'Arxiu Diocesà de Solsona (1101-1200), Barcelona, 2002, II, doc. 430, pp. 526-527. 
de frontales de altar ${ }^{24}$. En realidad, gracias a los registros testamentarios es posible reconocer la existencia de algunas piezas que hasta ahora habían pasado bastante desapercibidas a la historiografía, que suele centrar su interés en los frontales más conocidos y bien documentados ${ }^{25}$.

Por lo menos cuatro nuevos frontales se pueden identificar con cierta seguridad, dos de ellos mencionados a finales del s. X, y otros dos ya en el s. XI. Los primeros son el frontal de la canónica gerundense de Santa Maria d'Amer, cuyo encargo es mencionado en un testamento del año $986^{26}$, y el frontal de la iglesia monástica de Sant Pere de Maleses en el condado del Pallars, para cuya plata se menciona un legado del conde Borrell I en una fecha indeterminada de finales de la centuria déci$\mathrm{ma}^{27}$. Los dos segundos son la tabla de altar que existía en el año 1050 en la iglesia monástica de Santa Maria de Serrateix, tan vinculada a los condes de Cerdanya ${ }^{28}$, y la que decoraba el altar mayor de la iglesia abacial del poderoso cenobio urgelitano de Sant Sadurní de Tavèrnoles. La historia de esta última resulta especialmente singular: aparece documentada en el acta de consagración de la iglesia, un documento falso fechado en el año 1040 pero redactado a mediados de s. XII, que sin embargo utiliza documentos auténticos de la centuria anterior, entre los cuales un breve inventario eclesiástico en el que se cita el frontal ("tabula I de argento"). La existencia de la pieza queda atestiguada en un testamento de 1066 que incluye legado ad tabula ${ }^{29}$, y posiblemente también en la relación de los donativos realizados por Arnau Mir de Tost tras la muerte de su esposa Arsenda en 1068, que incluye cierta cantidad de plata para el mismo cenobio, "ad ipsam tabulam" ${ }^{30}$. En un documento algo posterior, fechado en 1092, se menciona cómo los monjes de Tavèrnoles entregaron el frontal al conde Ermengol IV para que este utilizara las 18 libras de plata que contenía (cantidad nada despreciable: casi seis kilos) en la financiación de la ardua conquista de la plaza musulmana de Balaguer ${ }^{31}$. A mediados de $\mathrm{s}$. XII se realizaría en Tavèrnoles

24 Incluso cabría plantearse la posibilidad de suponer a los frontales cierto tipo de personalidad jurídica, para regular su capacidad para la recepción de donativos, tal y como parece que ocurría con algunas imágenes esculpidas, según lo planteado por J.-M. SANSTERRE, "Donations de biens-fonds à des images au XI ${ }^{\mathrm{e}}$ siècle: à propos de quelques mentions relevées récemment", Revue belge de philologie et d'histoire, 75, 2 (1997), pp. 329-332.

25 El repertorio es bastante amplio. Hay frontales en las catedrales de Girona, Barcelona, Vic, Elna y Seu d'Urgell, y en las iglesias monásticas de Ripoll, Cuixà, Canigó, Sant Cugat del Vallès y Sant Feliu de Guíxols. Una panorámica (algo antigua) sobre la cuestión en: J. SUBÍAS Y GALTER, "Els Pal·lis. Or i argent a l'orfebreria romànica catalana”, Miscel-lània Puig $i$ Cadafalch, Barcelona, 1947-1951, I, pp. 373-382.

26 E. JUNYENT, Diplomatari de la catedral de Vic: $s$. IX-X, Vic, 1980-1996, doc. 524, fasc. 4, pp. 445447.

27 M. RAVINA, "Documentos de Pallars en el Archivo Ducal de Medinaceli (Sevilla)", Miscelánea de estudios dedicados al Profesor Antonio Marín Ocete (1900-1972), Granada, 1974, II, doc. 3, pp. 919-920.

28 J. BOLÓS, Diplomatari del monestir de Santa Maria de Serrateix (segles X-XV), Barcelona, 2006, doc. 95, pp. 173-174.

29 C. BARAUT, “Els documents, dels anys 1051-1075, de 1'Arxiu Capitular d'Urgell”, Urgellia, 6 (1983), doc. 795, pp. 159-160.

30 R. CHESÉ, op. cit., 2011, I, doc. 88, p. 331-333.

31 C. BARAUT, "Diplomatari del monestir de Sant Sadurní de Tavèrnoles”, Urgellia, 12 (1994-1995), doc. 100, pp. 170-171. A cambio de la plata, el cenobio recibe varias tierras y bienes, incluyendo una mezquita balaguerense para ser reconvertida en iglesia dedicada a San Saturnino. 
otro frontal de altar para sustituir la obra donada al conde, aunque ya no sería de materiales preciosos sino de simple madera pintada; este segundo frontal-magnífico-se conserva todavía hoy, en el MNAC ${ }^{32}$.

Las fórmulas utilizadas en los testamentos permiten asegurar en un cierto número de casos que los legados se condicionan bien a la fabricación o bien al enriquecimiento de dichos frontales. Por ejemplo, en el conocido testamento de la condesa Ermessenda de Barcelona (1057) se ordena la creación claramente ex novo de una tabla de altar con la plata concedida al cenobio de Sant Feliu de Guíxols: "faciant fieri tabulam argenteam cum ipso argento quod eis dedit"33. En 1083, el obispo de Urgell Guillem Arnau de Montferrer concede su pomo de espada de oro al frontal que decoraba ya el altar mayor de su catedral, lo que queda perfectamente detallado: "ad tabulam que est ante altare" 34 . Más tarde, en el testamento de 1130 del conde barcelonés Ramon Berenguer III, incluso se especifica un legado en rentas para la reforma ("pro emendationi") del frontal del monasterio de Sant Cugat del Vallès, cuya plata quizás podríamos suponer que había tomado prestada el conde, pues dicho legado se hace también específicamente "pro remedio anima" 35 .

\section{Conclusiones}

Del análisis presentado hasta el momento se derivan tres o cuatro conclusiones creo que de notable interés para el conocimiento de la orfebrería románica en Cataluña. Las enumero a continuación.

1) Debe insistirse, primero, la importancia de la plata como material de las artes suntuarias del románico. Es bueno ahondar en ello, porque la historiografía tiende a significar la oposición entre una orfebrería románica preferentemente áurea y una orfebrería gótica fundamentada en el trabajo argénteo gracias al descubrimiento y explotación de grandes yacimientos mineros de Centroeuropa. Sin embargo, la plata ya es el metal por excelencia de la orfebrería anterior a 1200 (y en la anterior al año 1000), mientras que el oro queda reservado solo, antes y después, a los proyectos más ambiciosos y a los grandes promotores.

2) En segundo lugar, cabe subrayar el valor de las piezas orfebres como activos preferentes en la transmisión patrimonial entre los ámbitos laico y eclesiástico de la sociedad del Medievo. Los testamentos analizados revelan siempre una transmisión de lo profano hacia lo clerical, pero hay que tener en cuenta las contrapartidas y los mecanismos que existían para desarrollar el camino inverso, es decir para que la ri-

32 Su peculiar iconografía, una serie de nueve obispos nimbados, ha sido relacionado convincentemente por Anna Orriols con la decoración de las falsas actas del concilio de Jaca, elaboradas a mediados de s. XII: A. ORRIOLS, "Episcopal iconography at the Tavèrnoles altar-frontal", Image and Altar, 1000-1300 (PNM Studies), Copenhague, 2014, pp. 121-145. Agradezco a la autora la consulta del texto previa a su publicación.

33 I. LLOP, op. cit., 2009, I, doc. 197, pp. 217-220.

34 C. BARAUT, "Els documents, dels anys 1093-1100, de l'Arxiu Capitular d'Urgell", Urgellia, 8 (19841985), doc. 1017, pp. 20-24.

35 I. BAIGES, G. FELIU y J.M. SALRACH, Els pergamins de l'Arxiu Comtal de Barcelona, de Ramon Berenguer II a Ramon Berenguer IV, Barcelona, 2010, III, doc. 631, pp. 1051-1057. 
queza atesorada por el estamento eclesiástico retornara al ámbito laico. Desde luego las fuentes (redactadas por eclesiásticos) mencionan poco estos caminos de retorno, y cuando lo hacen suelen adornar el relato para no subvertir el discurso moral y la legislación eclesiástica, que se oponía a la mercantilización de los objetos y bienes religiosos. Aún así, los préstamos y los empeños del patrimonio eclesiástico, incluso las ventas de objetos suntuarios, son muy habituales. Y a veces se mencionan claramente: en su testamento del año 1102, el conde Guillem Jordà de Cerdanya reconoce tener empeñado del monasterio de Sant Miquel de Cuixà un frontal de altar y un incensario de plata por valor de 38 libras, y asume como legado la restauración de ambas piezas y su retorno al cenobio ${ }^{36}$.

Este documento, por cierto, invita a recelar de los conmovedores discursos eclesiásticos sobre los dramáticos expolios de los tesoros catedralicios o monásticos por parte de la nobleza feudal. El tema merece, sin duda, un estudio en profundidad, pero puede asegurarse que excepto en el caso de los saqueos explícitamente forzados y violentos, dichos expolios no parecen ser el resultado de la brutalidad señorial o del abuso de poder de las élites laicas como continuamente se interpreta. Todo lo contrario, hay que entenderlos dentro del sistema de intertransmisión financiera fundado en los objetos preciosos que vincula el ámbito religioso y el profano, sistema conocido y asumido por todo el mundo. Otra cosa es la manera como se presenta dicho sistema en los documentos, donde evidentemente no puede quedar explícito el uso económico de los objetos litúrgicos por parte de las instituciones eclesiásticas, uso al que se oponía el grueso de la tradición legislativa de la Iglesia ${ }^{37}$. La desaparición del frontal de Tavèrnoles mencionado más arriba se integra en este tipo de procesos, aunque el caso más célebre, en Cataluña, es el de la plata del altar mayor de Santa Maria de Ripoll, prestada a en 1141 a Ramon Berenguer IV para financiar las campañas militares de la casa de Barcelona $^{38}$.

3) Una tercera conclusión derivada del estudio de los testamentos refiere a los procesos de fabricación. Se constata que el procedimiento habitual para la creación de objetos suntuarios se basa en el reaprovechamiento de los materiales de otras piezas. Estas se fundían sin reparo alguno, especialmente las de uso profano, y con los metales recuperados se daba forma a la pieza nueva. No hace falta ver en este tipo de procesos (que, por cierto, se mantienen igual para la Baja Edad Media, donde están todavía más y mejor documentados ${ }^{39}$ ) atisbo alguno de indiferencia o menosprecio hacia las obras de arte, pues es probable que lo fundido se considerase sencillamente antiguo, y está claro que la mayoría de las piezas no debían tener un especial desarrollo estético.

36 F. MIQUEL I ROSSELL, Liber Feudorum Maior: cartulario real que se conserva en el Archivo de la Corona de Aragón, Barcelona, 1945-1947, II, doc. 695, pp. 207-209.

37 Debido a su carácter sagrado, la alienación de ornamenta estaba rígidamente regulada, y generalmente dependía de la aprobación de las altas jerarquías, cuando no de Roma como precisa el canon 46 del concilio Letrán IV. La reiteración de advertencias en contra de ventas o empeños que se registran en las actas de los concilios episcopales y en otros documentos desde luego revelan su elevada frecuencia. Sobre la legislación canónica: A. COLY, “Aliénation”, Dictionnaire de Droit Canonique, París, 1935-1965, I, cols. $405-415$ (en especial col. 404). Véase también, aunque en una cronología tardomedieval: J. BAUCELLS, Vivir en la Edad Media, Barcelona, 2004, I, pp. 859-866.

38 La plata del ciborio, de unas cubiertas de Evangeliario y de una cruz se concede a cambio de las rentas de un alodio condal en Molló, gracias a las cuales se pudo fabricar, diez años más tarde, otro conjunto ornamental para el altar mayor: F.X. ALTÉS, "La institució de la festa de Santa Maria en dissabte i la renovació de l'altar major del monestir de Ripoll a mitjan segle XII”, Studia monastica, 44-1 (2002), pp. 57-96.

39 Véase, por ejemplo: I. DE LA FUENTE, "La revenda d'objectes d'argent a la Barcelona baix-medieval", Acta historica et archaeologica Medievalia, 18 (1997), p. 385. 
En cualquier caso, por encima del gusto artístico predomina siempre la valoración material de los objetos y su posible condición como materia prima de otros bienes. Ciertamente debieron existir también otras vías para la aportación de materiales, como el comercio y especialmente la extracción minera a pequeña escala, pero sin embargo estos nunca fueron verdaderamente importantes ${ }^{40}$.

4) La reutilización de los metales en la fabricación de piezas nuevas, y lo habitual de las reformas y embellecimientos de las piezas documentadas, permiten suponer una conclusión final: confirman, creo, la existencia de talleres de producción orfebre en territorio catalán durante la plena Edad Media. No es baladí recalcar esta afirmación, puesto que la historiografía tiende en general a infravalorar la producción local en esta época antigua y a considerar que cualquier tipo de producto suntuario documentado, particularmente los de cierta envergadura (caso de los frontales de altar), había de ser resultado de la importación.

Es verdad que la realidad de estos talleres autóctonos no viene confirmada de forma explícita en los textos, ni tampoco arqueológicamente ${ }^{41}$, pero sin ellos hubiera sido imposible la existencia de un mercado orfebre de tanta intensidad y tan proclive a los intercambios, a las fundiciones y a la refabricación de objetos como el que se observa en las fuentes. Claro que se importaban algunas piezas, quizás algunas especialmente ricas inicialmente, y luego, ya en el s. XIII, sin duda la barata y vivaz producción en cobre esmaltado de Limoges. Pero lo importado no parece que fuera porcentualmente tan significativo como a menudo se plantea, y los productos surgidos de los talleres locales habían de controlar eficazmente los mercados. La ubicación y el carácter de dichos talleres y de sus artífices (¿predominaron los de contexto monástico, por ejemplo?) es algo complejo de analizar, y a lo que habrá que dedicar otro tiempo.

\footnotetext{
40 La extracción de metales preciosos, aunque a muy pequeña escala, es habitual en toda Europa. En Cataluña se conocen minas de plata en la zona más oriental de los Pirineos: C. VERNA-NAVARRE, "Esquisse d'une histoire des mines et de la métallurgie monastiques dans les Pyrénées (IX'-première moitié du XVI ${ }^{\mathrm{e}}$ siècle)", Moines et métallurgie dans la France médiévale, París, 1991, pp. 45-58.

41 Sí se han localizado un par de hornos dedicados al trabajo del bronce, uno en Sant Andreu d'Òrrius: I. PADILLA, "Informe preliminar de les excavacions fetes a Sant Andreu d'Òrrius", Excavaciones arqueológicas, 2 (1983), pp. 11-53; y otro en el claustro de la iglesia de Santa Maria de Manresa, pero que se suponen dedicados a la fabricación de campanas: M. SANCHO, A. CABALLÉ y J. PUJADES, "Les restes arqueològiques d'un forn de bronze d'època medieval de la Seu de Manresa", Acta historica et archaeologica Mediaevalia, 11-12 (1991), pp. 485-493.
} 